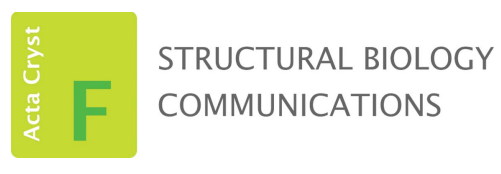

ISSN 2053-230X

\section{Structural studies of the unusual metal-ion site of the GH124 endoglucanase from Ruminiclostridium thermocellum}

\author{
Saioa Urresti, ${ }^{a}$ Alan Cartmell, ${ }^{\mathrm{b}}$ Feng Liu, ${ }^{\mathrm{c}}$ Paul H. Walton ${ }^{\mathrm{d} *}$ and Gideon J. Davies ${ }^{\mathrm{a} *}$ \\ ${ }^{a}$ York Structural Biology Laboratory, Department of Chemistry, University of York, York YO10 5DD, England, ${ }^{\mathbf{b}}$ Institute \\ for Cell and Molecular Biosciences, Newcastle University, Newcastle upon Tyne NE1 7RU, England, 'Department of \\ Chemistry, University of British Columbia, Vancouver V6T 1Z1, Canada, and ${ }^{\mathrm{d} D e p a r t m e n t ~ o f ~ C h e m i s t r y, ~ U n i v e r s i t y ~ o f ~}$ \\ York, York YO10 5DD, England. *Correspondence e-mail: paul.walton@york.ac.uk, gideon.davies@york.ac.uk
}

The recent discovery of 'lytic' polysaccharide monooxygenases, copperdependent enzymes for biomass degradation, has provided new impetus for the analysis of unusual metal-ion sites in carbohydrate-active enzymes. In this context, the CAZY family GH124 endoglucanase from Ruminiclostridium thermocellum contains an unusual metal-ion site, which was originally modelled as a $\mathrm{Ca}^{2+}$ site but features aspartic acid, asparagine and two histidine imidazoles as coordinating residues, which are more consistent with a transition-metal binding environment. It was sought to analyse whether the GH124 metal-ion site might accommodate other metals. It is demonstrated through thermal unfolding experiments that this metal-ion site can accommodate a range of transition metals $\left(\mathrm{Fe}^{2+}, \mathrm{Cu}^{2+}, \mathrm{Mn}^{2+}\right.$ and $\left.\mathrm{Ni}^{2+}\right)$, whilst the three-dimensional structure and mass spectrometry show that one of the histidines is partially covalently modified and is present as a 2-oxohistidine residue; a feature that is rarely observed but that is believed to be involved in an 'off-switch' to transition-metal binding. Atomic resolution $(<1.1 \AA)$ complexes define the metal-ion site and also reveal the binding of an unusual fructosylated oligosaccharide, which was presumably present as a contaminant in the cellohexaose used for crystallization. Although it has not been possible to detect a biological role for the unusual metal-ion site, this work highlights the need to study some of the many metal-ion sites in carbohydrate-active enzymes that have long been overlooked or previously mis-assigned.

\section{Introduction}

Unarguably one of the most important recent developments in our understanding of the degradation of plant, and other recalcitrant, polysaccharides has been the discovery of (lytic) polysaccharide monooxygenases (LPMOs, sometimes termed PMOs). LPMOs are oxygenases that harness an unusual copper-containing 'histidine-brace' active centre to generate reactive oxygen species (from $\mathrm{O}_{2}$ or, under specific laboratory conditions, $\mathrm{H}_{2} \mathrm{O}_{2}$ ), ultimately leading to oxidative chain cleavage (reviewed, for example, in Horn et al., 2012; Lo Leggio et al., 2012; Span \& Marletta, 2015; Walton \& Davies, 2016). These enzymes are now classified in the Carbohydrate-Active enZymes (CAZy) classification as 'auxiliary enzyme' (Levasseur et al., 2013) activities AA9, AA10, AA11, AA13, AA14 and AA15. The first structure of what is now known to be an AA10 LPMO (then believed to be a noncatalytic chitinbinding domain; Vaaje-Kolstad et al., 2005) revealed an unusual metal-ion site featuring two histidine $\mathrm{N}$ atoms and the amino-terminal amine coordinating a metal that was modelled as an $\mathrm{Na}^{+}$ion (PDB entry 2ben), thus not arousing the interest 
Table 1

Macromolecule-production information.

\begin{tabular}{|c|c|}
\hline Source organism & R. thermocellum \\
\hline DNA source & Brás et al. (2011) \\
\hline Forward primer & $\begin{array}{l}\text { CTGTTCCAGGGACCAGCACCTGCAAATACA } \\
\text { CAATCC }\end{array}$ \\
\hline Reverse primer & $\begin{array}{l}\text { GGAGATTTATTACTAATCACATATGGCTAG } \\
\quad \text { C }\end{array}$ \\
\hline Cloning vector & pET-28a \\
\hline Expression vector & $\begin{array}{l}\text { Modified pET-28a containing } 3 \mathrm{C} \text { protease } \\
\text { site }\end{array}$ \\
\hline Expression host & E. coli $\mathrm{BL} 21(\mathrm{DE} 3) \mathrm{pLysS}$ \\
\hline $\begin{array}{l}\text { Complete amino-acid sequence } \\
\text { of the construct produced } \dagger\end{array}$ & $\begin{array}{l}\text { HHHHHHSSGLEVLFQGPAPANTQSGILNDG } \\
\text { YFPPGTSKHELIARASSLKVSEVKAIIK } \\
\text { KQVDEHWDVIRDVCGFKNKEVAYFFFG } \\
\text { MATRESTFRAATETGSGASHAFGPLQTA } \\
\text { ETAYANANPNYMPEHNVPEMHQYDFTEY } \\
\text { NFYDVGISVHMGIRHFLHFARLAKEKYS } \\
\text { GRDIARHGLMGYNTGWIDGADESWIVRY } \\
\text { ADETAALGAWYLRNNHMSDDEFTWDTDP } \\
\text { RVDRSNPWEIYY }\end{array}$ \\
\hline
\end{tabular}

$\dagger$ The histidine tag is in bold. The $3 \mathrm{C}$ protease recognition site is underlined (cleavage occurs between $\mathrm{Q}$ and $\mathrm{G}$ ). After $3 \mathrm{C}$ cleavage, the residues GPA remain at the $\mathrm{N}$-terminus, preceding the $R t \mathrm{GH} 124$ sequence.

of the redox-enzyme community. Indeed, when it was shown that the function of these enzymes was the oxidative cleavage of polysaccharides harnessing molecular oxygen (VaajeKolstad et al., 2010), it was still claimed that any one of $\mathrm{Na}^{+}$, $\mathrm{Ca}^{2+}$ or $\mathrm{Mg}^{2+}$ was the potential metal ion at the active site. Other work on fungal AA9 enzymes had also implicated $\mathrm{Ni}^{2+}$, $\mathrm{Mn}^{2+} \mathrm{Co}^{2+}$ or $\mathrm{Mg}^{2+}$ in their structures or mode of action, leading to considerable confusion in the field (Karkehabadi et al., 2008; Harris et al., 2010). It was only in 2011 that Quinlan and coworkers showed that the related AA9 enzymes were copper-dependent enzymes (Quinlan et al., 2011), as subsequently confirmed by others (Phillips et al., 2011), that the true metal ion for LPMOs became known (Fig. 1). A further finding of this latter study was that one of the coordinating residues in fungal AA9 enzymes is a covalently modified, methylated histidine (Quinlan et al., 2011; Fig. 1).

Modelling of metal-ion sites in protein three-dimensional structures can be fraught with difficulty, and many metal-ion sites are both misinterpreted and potentially 'contaminated' with crystallization metal ions or metals used in affinitypurification steps (Schöneich, 2000; Zheng et al., 2008, 2014; Chruszcz et al., 2010). So, mindful of the potential of metal-ion sites to provide novel catalytic functions, of the environment of such sites to feature novel, modified amino acids, and of the possibility that such sites may have been overlooked in the original structural determinations, we were minded to examine the deposited three-dimensional structures for some represented enzyme families to look for such features.

Thus, whilst inspecting the PDB for unusual metal-ion sites, our attention was drawn to a metal site in the Ruminiclostridium thermocellum (the organism previously known as Clostridium thermocellum; Yutin \& Galperin, 2013) GH124 endoglucanase GH124A. This enzyme is not part of the megadalton cellulosome complex of the organism. Instead, its modular structure consists of a cell-surface attachment 'dockerin' domain followed by a CAZY GH124 catalytic domain (which, in seminal work, Brás and coworkers showed to be an inverting endoglucanase; Brás et al., 2011). This work also identified the active centre and revealed the first threedimensional structure for the catalytic domain of a GH124 family member (reviewed in CAZypedia; The CAZypedia Consortium, 2018).

Initially modelled as a $\mathrm{Ca}^{2+}$ site in $\mathrm{PDB}$ entry 2xqo, we noticed that the geometry and coordination, featuring aspartic acid, asparagine and two histidine imidazoles, was more likely to indicate a transition-metal site. Furthermore, unusual unmodelled density at His157 led us to believe that this amino acid was also covalently modified, although in a manner different to that seen in LPMOs. We therefore sought to determine whether this metal-ion site could accommodate transition metals and how they might impact on stability, and to probe the unusual histidine modification.

Here, we show that the metal-ion site of GH124 can accommodate a variety of metal ions (but not $\mathrm{Ca}^{2+}$ ) and that the histidine is modified by a carbonyl group at $\mathrm{C} 2$ to make 2-oxohistidine (but only at a fraction of approximately 0.5). Metal binding also occurs with a stoichiometry of

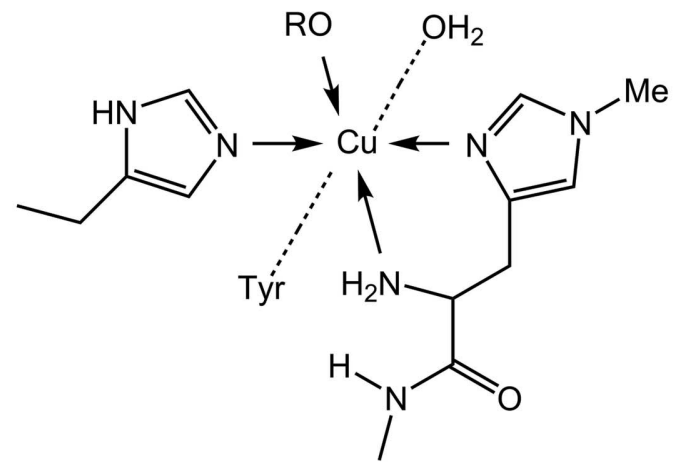

(a)

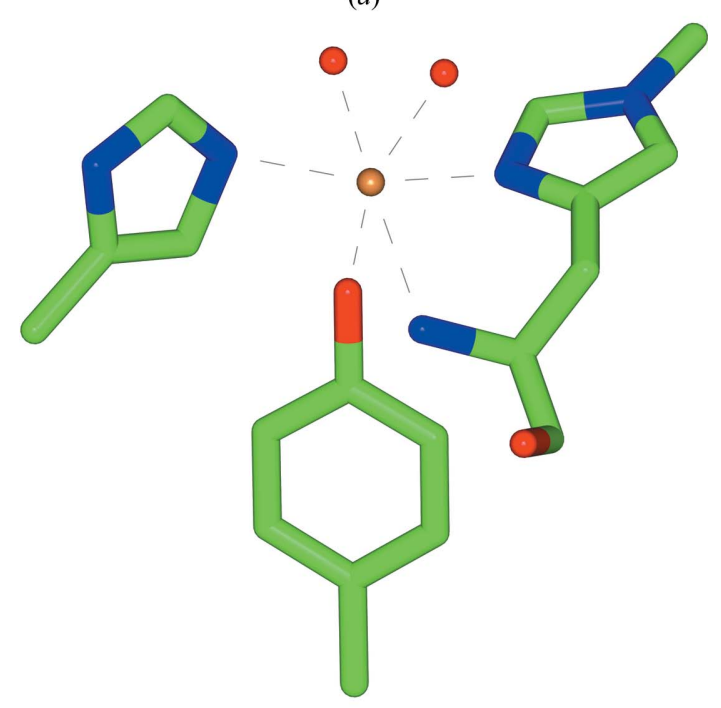

(b)

Figure 1

Model metal-ion site in LPMOs (PDB entry 2yet). (a) Schematic and (b) crystal structure of the copper-binding site from Thermoascus aurantiacus, TaAA9 (previously known as TaGH61), including the typical histidine brace and a methylated His1 (Quinlan et al., 2011). 
Table 2

Crystallization.

\begin{tabular}{|c|c|c|}
\hline & RtGH124-G3-Mn (PDB entry 6g1g) & RtGH124-G5F-Mn (PDB entry 6g1i) \\
\hline Method & Vapour diffusion, sitting drop & Vapour diffusion, sitting drop \\
\hline Plate type & 96-well 2-drop MRC & 96-well 2-drop MRC \\
\hline Temperature $(\mathrm{K})$ & 293 & 293 \\
\hline Protein concentration $\left(\mathrm{mg} \mathrm{ml}^{-1}\right)$ & 40 & 40 \\
\hline Volume and ratio of drop & $54 \mu \mathrm{l}, 1: 1$ ratio & $54 \mu \mathrm{l}, 1: 1$ ratio \\
\hline Volume of reservoir $(\mathrm{nl})$ & 400 & 400 \\
\hline Buffer composition of protein solution & $20 \mathrm{~m} M$ Tris $\mathrm{pH} 7.5,6.7 \mathrm{~m} M \mathrm{G} 3$ & $20 \mathrm{~m} M$ Tris $\mathrm{pH} 7.5,6.7 \mathrm{~m} M$ G5F \\
\hline Composition of reservoir solution & $\begin{array}{l}\text { 12\% Tacsimate } \mathrm{pH} 5.0,18 \% \text { PEG } 3350, \\
2 \mathrm{~m} M \text { manganese(II) acetate }\end{array}$ & $\begin{array}{l}6 \% \text { Tacsimate pH } 5.0,20 \% \text { PEG } 3350 \text {, } \\
2 \mathrm{~m} M \text { manganese(II) acetate }\end{array}$ \\
\hline Cryoprotection buffer solution & $\begin{array}{l}\text { 14\% Tacsimate } \mathrm{pH} 5.0,19 \% \text { PEG } 3350, \\
2 \mathrm{~m} M \text { manganese(II) acetate }\end{array}$ & $\begin{array}{l}8 \% \text { Tacsimate pH 5.0, } 21 \% \text { PEG } 3350, \\
2 \mathrm{~m} M \text { manganese(II) acetate }\end{array}$ \\
\hline
\end{tabular}

approximately 0.5 (in solution by ITC and in the crystal through occupancy refinement) and we are thus unable to deconvolute whether the 2-oxohistidine is required for metal binding or antithetical to it. In passing, we determined a series of structures of GH124 co-crystallized with cellohexaose which revealed the unusual binding of a contaminant, a terminally fructosylated cellooligosaccharide, with unambiguous density at $\sim 1 \AA$ resolution. The work highlights the hidden world of metal-ion sites and unusual coordination geometries and encourages further study of these phenomena.

\section{Materials and methods}

\subsection{Macromolecule production}

The original rtgh124-containing plasmid was kindly provided by Professor Harry Gilbert's laboratory (Brás et al., 2011). This clone lacks the dockerin domain, but expresses 23 extra residues at the $\mathrm{N}$-terminus, including a noncleavable His tag. The gene was subcloned using the ligation-independent cloning technique on a modified pET-28a plasmid containing a His tag $(6 \times$ His $)$ followed by a $3 \mathrm{C}$ protease recognition site at the N-terminus. Thus, the new clone was His-3C-RtGH124 (see Table 1). The cleaved sequence has only three extra residues preceding the $R t \mathrm{GH} 124$ protein (Gly-Pro-Ala). Furthermore, we have applied the UniProt numbering (A3DCJ4), which includes the first 130 amino acids of the dockerin domain. Therefore, the numbering of this construct is shifted from the sequence reported by Brás et al. (2011) by exactly 107 residues. Competent Escherichia coli BL21(DE3)pLysS cells were transformed by heat shock with the recombinant plasmid for protein production. The starter culture was incubated in $300 \mathrm{ml}$ Luria-Bertani (LB) broth in the presence of $30 \mu \mathrm{g} \mathrm{ml}^{-1}$ kanamycin and $35 \mu \mathrm{g} \mathrm{ml}^{-1}$

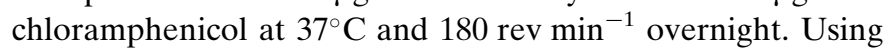
this as an inoculum, protein production was induced by the addition of $1 \mathrm{~m} M$ isopropyl $\beta$-D-1-thiogalactopyranoside (IPTG) to a total of 31 of LB with the same antibiotics, temperature and shaking speed for $16 \mathrm{~h}$. The cells were harvested by centrifugation at $5000 \mathrm{~g}$ for $15 \mathrm{~min}$. The pellets were resuspended in $100 \mathrm{ml}$ buffer $A(50 \mathrm{~m} M$ Tris $\mathrm{pH} 7.5$, $300 \mathrm{~m} M \mathrm{NaCl}, 20 \mathrm{~m} M$ imidazole) with the addition of one EDTA-free protease-inhibitor cocktail tablet (Roche). The cell suspension was then sonicated in an ice bath using five cycles of 60/90 s on/off pulses in a Soniprep 150 Plus sonicator (MSE). $50 \mathrm{ml}$ of sample was incubated with $3 \mu$ Benzonase (Santa Cruz Biotechnology) for $20 \mathrm{~min}$ at room temperature and then centrifuged $(6000 \mathrm{~g}, 20 \mathrm{~min})$ and the supernatant filtered $(45 \mu \mathrm{m})$. The filtrate was applied onto a $5 \mathrm{ml}$ HisTrap column (GE Healthcare) pre-equilibrated in buffer $A$. The protein was eluted with a gradient to $500 \mathrm{~m} M$ imidazole in the same buffer and buffer-exchanged using a $30 \mathrm{kDa}$ Vivaspin 20 filter unit (Sartorius). The low-salt and low-imidazole sample was incubated with a 1:20 ratio of His-tagged $3 \mathrm{C}$ protease for $18 \mathrm{~h}$ at $20^{\circ} \mathrm{C}$ at minimum rocking/rotating speed. The sample was then applied onto a second $5 \mathrm{ml}$ HisTrap column (in the same buffer). The cleaved protein, pooled from the flowthrough, was then buffer-exchanged and concentrated using a $10 \mathrm{kDa}$ Vivaspin 20 filter unit. A final volume of $2 \mathrm{ml}$ protein in $50 \mathrm{mM}$ Tris $\mathrm{pH} 7.5$ was incubated with excess ethylenediaminetetraacetic acid (EDTA; $5 \mathrm{mM}$ ) for $18 \mathrm{~h}$ at $4{ }^{\circ} \mathrm{C}$ with the aim of chelating any residual metal from the sample. Finally, the sample was run through a Superdex 75 16/60 gelfiltration column (GE Healthcare) previously equilibrated with demetallated buffer composed of $20 \mathrm{mM}$ Tris $\mathrm{pH} 7.5$, $150 \mathrm{mM} \mathrm{NaCl}$. The eluted protein was pooled and concentrated using a $10 \mathrm{kDa}$ Vivaspin 0.5 filter unit. The protein purity was confirmed by $12.5 \%$ SDS-PAGE.

\subsection{Crystallization}

An optimization screen was designed for crystal growth, based on the conditions reported in Brás et al. (2011), as a gradient of PEG 3350 (16-26\%) and Tacsimate buffer $\mathrm{pH} 5.0$ (6-12\%; Hampton Research). Either $2 \mathrm{~m} M$ metal salt [iron(II) chloride, manganese(II) acetate, nickel(II) chloride, calcium chloride or copper(II) chloride] or an equivalent volume of buffer (no metal) was added to each screen. Protein at $40 \mathrm{mg} \mathrm{ml}^{-1}$ was incubated with $6.7 \mathrm{~m} M$ of either cellotriose (G3; Megazyme) or cellohexaose (G6; Megazyme; this substrate turned out to be contaminated as revealed by threedimensional analyses and will therefore be referred to as G5F, see below) in $20 \mathrm{~m} M$ Tris $\mathrm{pH} 7.5$ for $18 \mathrm{~h}$ prior to crystal plate setup. Crystals grew at $20^{\circ} \mathrm{C}$, mainly in clusters, after $3 \mathrm{~d}$. Crystals of a reasonable size $(\sim 100 \mathrm{~nm})$ were harvested from several conditions and flash-cooled in liquid nitrogen after cryoprotection with a solution composed of $2 \mathrm{mM}$ metal salt and concentrations of Tacsimate and PEG 3350 that were 
Table 3

Data collection and processing.

Values in parentheses are for the outer shell.

\begin{tabular}{|c|c|c|}
\hline & $\begin{array}{l}\text { RtGH124-G3-Mn } \\
\text { (PDB entry 6g1g) }\end{array}$ & $\begin{array}{l}\text { RtGH124-G5F-Mn } \\
\text { (PDB entry 6g1i) }\end{array}$ \\
\hline Diffraction source & I02, DLS & I02, DLS \\
\hline Wavelength $(\AA)$ & 0.98 & 0.98 \\
\hline Temperature $(\mathrm{K})$ & 100 & 100 \\
\hline Detector & PILATUS 6 M-F & PILATUS 6 M-F \\
\hline Rotation range per image $\left({ }^{\circ}\right)$ & 0.10 & 0.10 \\
\hline Total rotation range $\left({ }^{\circ}\right)$ & 180 & 180 \\
\hline Exposure time per image (s) & 0.04 & 0.04 \\
\hline Space group & $P 3_{2} 21$ & $P 2_{1} 2_{1} 2_{1}$ \\
\hline$a, b, c(\AA)$ & $73.92,73.92,74.94$ & $74.14,74.14,77.33$ \\
\hline$\alpha, \beta, \gamma\left({ }^{\circ}\right)$ & $90,90,120$ & $90,90,90$ \\
\hline Mosaicity $\left({ }^{\circ}\right)$ & 0.14 & 0.25 \\
\hline Resolution range $(\AA)$ & $74.92-1.03$ (1.06-1.03) & $74.17-0.99(1.01-0.99)$ \\
\hline Total No. of reflections & $1021012(29079)$ & 1203487 (15629) \\
\hline No. of unique reflections & $113462(5523)$ & $215828(6811)$ \\
\hline Completeness (\%) & $99.9(98.7)$ & $95.3(62.0)$ \\
\hline Multiplicity & $9.0(5.3)$ & $5.6(2.3)$ \\
\hline$\langle I / \sigma(I)\rangle$ & $15.9(1.5)$ & $12.6(1.0)$ \\
\hline$R_{\text {p.i.m. }}$ & $0.02(0.44)$ & $0.02(0.63)$ \\
\hline $\mathrm{CC}_{1 / 2}$ & $0.9(0.6)$ & $0.9(0.5)$ \\
\hline $\begin{array}{l}\text { Overall } B \text { factor from } \\
\text { Wilson plot }\left(\AA^{2}\right)\end{array}$ & 10 & 7 \\
\hline
\end{tabular}

$2 \%(v / v)$ and $1 \%(w / v)$ higher, respectively, than those in the mother liquor (see Table 2). Two representative structures with the ligands G3 and G5F have been deposited with PDB codes $6 \mathrm{~g} 1 \mathrm{~g}$ and $6 \mathrm{~g} 1 \mathrm{i}$, respectively, and are used in the reports and figures in this paper.

$\beta$-1,4-linked Glc-Fru was synthesized following the conditions described previously in the literature (Hicks et al., 1983). Glc-Glc-Fru was prepared by feeding Glc-Fru to an Agrobacterium sp. $\beta$-glucosidase-derived glycosynthase Abg2F6 (essentially as described by Kim et al., 2004) in the presence of $\alpha$-glucosyl fluoride $(\alpha-\mathrm{GlcF})$. Glc-Fru and Glc-Glc-Fru were included in co-crystallization, but no crystals grew under these conditions.

\subsection{Data collection and processing}

Diffraction data (Table 3) were collected on beamline I02 at Diamond Light Source (DLS), Oxfordshire, England. In general, data sets were collected at a wavelength of $0.979 \AA$. $\mathrm{X}$-ray fluorescence (XRF) spectra of the crystals were taken in situ during data collection to confirm the presence and nature of the metals in the cryoloop. Data sets were automatically indexed and integrated with $X D S$ (Kabsch, 2010) and scaled with AIMLESS using xia2 (Winter, 2010) at DLS.

\subsection{Structure solution and refinement}

XRF data were analysed with the $P y M C A$ software (Solé et al., 2007). Autoprocessed data sets were solved and refined using the CCP4i2 GUI (Potterton et al., 2018; Table 4). The original structure reported by Brás et al. (2011) was initially truncated with Sculptor (Bunkóczi \& Read, 2011) and used as a model for molecular replacement with MOLREP (Vagin \& Teplyakov, 2010). Structures were refined with several cycles of REFMAC5 (Murshudov et al., 2011) and Coot (Emsley et
Table 4

Structure solution and refinement.

\begin{tabular}{|c|c|c|}
\hline & $\begin{array}{l}\text { RtGH124-G3-Mn } \\
\text { (PDB entry 6g1g) }\end{array}$ & $\begin{array}{l}R t \mathrm{GH} 124-\mathrm{G} 5 \mathrm{~F}-\mathrm{Mn} \\
\text { (PDB entry 6g1i) }\end{array}$ \\
\hline Resolution range $(\AA)$ & $64.10-1.04$ & $53.59-0.99$ \\
\hline Completeness (\%) & 99.9 & 95.13 \\
\hline$\sigma$ Cutoff & None & None \\
\hline No. of reflections, working set & 107700 & 204772 \\
\hline No. of reflections, test set & 5714 & 10962 \\
\hline Final $R_{\text {cryst }}$ & 0.13 & 0.13 \\
\hline Final $R_{\text {free }}$ & 0.14 & 0.15 \\
\hline \multicolumn{3}{|l|}{ No. of non-H atoms } \\
\hline Protein & 1817 & 3589 \\
\hline Ion & 1 & 2 \\
\hline Ligand & 80 & 180 \\
\hline Water & 270 & 475 \\
\hline Total & 2168 & 4246 \\
\hline \multicolumn{3}{|l|}{ R.m.s. deviations } \\
\hline Bonds $(\AA)$ & 0.020 & 0.020 \\
\hline Angles $\left({ }^{\circ}\right)$ & 1.9 & 1.9 \\
\hline \multicolumn{3}{|l|}{ Average $B$ factors $\left(\AA^{2}\right)$} \\
\hline Protein & 15 & 11 \\
\hline Ion & 13 & 9 \\
\hline Ligand & 12 & 13 \\
\hline Water & 30 & 24 \\
\hline \multicolumn{3}{|l|}{ Ramachandran plot } \\
\hline Most favoured (\%) & 203 & 402 \\
\hline Allowed (\%) & 3 & 10 \\
\hline Outliers & 1 & 0 \\
\hline
\end{tabular}

al., 2010). Structures were generally validated using several tools in Coot and the European Protein Data Bank (PDBe; http://www.ebi.ac.uk/pdbe) validation tool. Sugars were validated with Privateer (Agirre et al., 2015) and metal correctness was tested with the CheckMyMetal (CMM) metalbinding site validation server (Zheng et al., 2014, 2017). Structural figures were made with CCP4mg (McNicholas et al., 2011).

\subsection{Differential scanning fluorimetry}

Two replicas of each sample were prepared in thin-wall $0.2 \mathrm{ml}$ tubes (Axygen) with $2 \mathrm{mg} \mathrm{ml}^{-1}(86 \mu M)$ pure metalfree $R t \mathrm{GH} 124$ protein in $50 \mathrm{~m} M$ Tris $\mathrm{pH} 7.5,150 \mathrm{~m} M \mathrm{NaCl}$ buffer (other buffers and $\mathrm{pH}$ values were also tried with similar results). A total of eight samples (plus replicas) were tested with protein only, $1 \mathrm{~m} M$ EDTA or one equivalent $(86 \mu M)$ of metal salt: iron(II) chloride, manganese(II) acetate, nickel(II) chloride, calcium chloride or copper(II) chloride. Samples $(15 \mu \mathrm{l})$ were mixed with $1000 \times$ of the fluorescent dye SYPRO Orange (Sigma-Aldrich) in a 1:1 ratio (final volume $30 \mu \mathrm{l}$ ). Measurements were performed using an Agilent MX3000P QPCR machine. The temperature was increased by $1{ }^{\circ} \mathrm{C}$ at $30 \mathrm{~s}$ intervals from 25 to $96^{\circ} \mathrm{C}$ and fluorescence was measured with excitation and emission wavelengths of 517 and $585 \mathrm{~nm}$, respectively.

\subsection{Electrospray (ESI-MS)}

The protein was tested by electrospray ionization mass spectrometry (ESI-MS) to observe the possible impact of metals on the His 264 modification. Briefly, $200 \mu M$ RtGH124 samples were pre-incubated with $0.5 \mathrm{~m} M$ EDTA, $200 \mu M$ 
metal salt [copper(II) chloride, iron(II) chloride, manganese(II) acetate or nickel(II) chloride] or no metal in pre-chelated $50 \mathrm{~m} M$ ammonium acetate $\mathrm{pH} 5.8$ buffer. The experiment was conducted on a Waters LCT Premier XE system with the MassLynx 4.1 software. The system was calibrated with sodium formate solution and calibration was verified and corrected with horse heart myoglobin $(16951.5 \pm 1.5 \mathrm{Da})$. Samples were diluted directly into acetonitrile-water-formic acid (50:50:0.1). Data were collected for 3 min over a scan range of $200-2000 \mathrm{~m} / \mathrm{z}$. The scans were combined and the baseline was subtracted. Data in the $m / z$ range containing the peak series were then processed using the Maxent 1 procedure over an appropriate mass range with suitable peak half-width settings determined from the raw data.

\subsection{Proteolysis and mass spectrometry}

To empirically localize the oxidized residue, a peptide proteolysed from $R t \mathrm{GH} 124$ was analysed by liquid chromatography and tandem mass spectrometry (LC-MS/MS). $25 \mu \mathrm{g}$ $R t$ GH124 was run on a $12.5 \%$ SDS-PAGE gel. The gel was stained in a clean box with SimplyBlue SafeStain (Invitrogen) and the appropriate band was cut. In-gel sequential digestion with trypsin and Asp-N endoproteases was performed after reduction with dithioerythritol and $S$-carbamidomethylation with iodoacetamide. The peptide mixture was loaded onto a nanoAcquity UPLC system (Waters) equipped with a nanoAcquity Symmetry C18 $5 \mu \mathrm{m}$ trap column $(180 \mu \mathrm{m} \times$ $20 \mathrm{~mm}$, Waters) and a nanoAcquity HSS T3 $1.8 \mu \mathrm{m} \mathrm{C18}$ capillary column $(75 \mu \mathrm{m} \times 250 \mathrm{~mm}$, Waters $)$. The trap wash solvent was $0.1 \%(v / v)$ aqueous formic acid and the trapping flow rate was $10 \mu \mathrm{min}^{-1}$. The trap was washed for $5 \mathrm{~min}$ before switching the flow to the capillary column. Separation used a gradient elution of two solvents [solvent $A$, aqueous $0.1 \%(v / v)$ formic acid; solvent $B$, acetonitrile containing $0.1 \%(v / v)$ formic acid]. The capillary column flow rate was

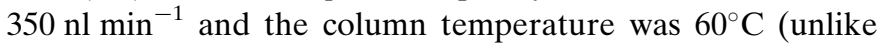
similar columns, we were able to run nanoAcquity HSS T3 $1.8 \mu \mathrm{m} \mathrm{C} 18$ capillary columns at $60^{\circ} \mathrm{C}$, which improves masstransfer rates and thus resolution and also reduces back pressure in the system, enabling a slight increase in flow rate). The gradient profile was a linear $2-35 \%$ solvent $B$ over 20 min. All runs then proceeded to a wash with $95 \%$ solvent $B$ for $2.5 \mathrm{~min}$. The column was returned to the initial conditions and re-equilibrated for $25 \mathrm{~min}$ before subsequent injections. The nanoLC system was interfaced with a maXis HD LC-MS/MS system (Bruker Daltonics) with a CaptiveSpray ionization source (Bruker Daltonics). Positive ESI-MS and MS/MS spectra were acquired using AutoMSMS mode. Instrument control, data acquisition and processing were performed using the Compass 1.7 software (microTOF Control, Hystar and DataAnalysis, Bruker Daltonics). The collision-energy and isolation-width settings were automatically calculated using the AutoMSMS fragmentation table, with an absolute threshold of 200 counts, preferred charge states 2-4 and singly charged ions excluded. A single MS/MS spectrum was acquired for each precursor and former target ions were excluded for $0.8 \mathrm{~min}$ unless the precursor intensity increased fourfold. Tandem mass spectra were searched against an inhouse database containing the expected protein sequence ( 842 sequences; 329761 residues) using a locally running copy of the Mascot program (v.2.5.1; Matrix Science) through the Bruker ProteinScape interface (v.2.1). The results were filtered to accept only peptides with an expect score of 0.05 or lower. Identification of oxidized histidine was confirmed by the manual validation of product-ion spectra against predicted $b$ and y-sequence ions.

\subsection{Isothermal titration calorimetry}

$380 \mu \mathrm{l}$ of pure pre-chelated $R t \mathrm{GH} 124$ protein $(60 \mu M)$ was titrated with $600 \mu M$ metal salt [copper(II) chloride, iron(II) chloride, manganese(II) acetate or nickel(II) chloride] in $1 \mu \mathrm{l}$ injections at $180 \mathrm{~s}$ intervals. The buffer used in both cell and syringe samples was $50 \mathrm{~m} M$ sodium acetate $\mathrm{pH}$ 5.0. Titrations were performed on a MicroCal Auto-ITC 200 (GE Healthcare) at $25^{\circ} \mathrm{C}$ and $750 \mathrm{rev} \mathrm{min}^{-1}$ stirring speed. Data were analysed with the Origin 7 software (OriginLab) and blanks were subtracted from the original data.

\subsection{Glucose- and fructose-detection methods}

Commercial sugars were detected by high-pressure anionexchange chromatography (HPAEC) with pulsed amperometric detection and were separated on a Carbopac PA1 guard and analytical column. Isocratic elution with $20 \mathrm{~m} M$ sodium hydroxide for $30 \mathrm{~min}$ and then with a $60 \%$ linear gradient of sodium acetate in $100 \mathrm{mM}$ sodium hydroxide over $60 \mathrm{~min}$ was used to separate the sugars. Sugars were detected using the carbohydrate standard quad waveform for electrochemical detection at a gold working electrode with an $\mathrm{Ag} / \mathrm{AgCl} \mathrm{pH}$ reference electrode. The glucose/mannose/fructose detection kit from Megazyme was also utilized to detect the relative amounts of glucose and fructose. This is a linked assay kit, with the detection of the appropriate monosaccharide linked $1: 1$ to the detection of NADH at $A_{340 \mathrm{~nm}}$ using an extinction coefficient of $6230 \mathrm{M}^{-1} \mathrm{~cm}^{-1}$.

\section{Results and discussion}

\subsection{Effect of the metal on thermal stability}

In order to provide a preliminary indication of metal binding, the thermal stability of $R t \mathrm{GH} 124$ was studied by differential scanning fluorimetry (Fig. 2). Both controls (protein and protein + EDTA) show a melting transition at $72^{\circ} \mathrm{C}$. Addition of $\mathrm{Ca}^{2+}$ did not shift the melting temperature, suggesting that this metal may not bind the protein, at any $\mathrm{pH}$ between $\mathrm{pH} 5$ and 7.5, and thus hints that the assignment of this metal in the original deposition may be misleading. In contrast, the melting temperature of $R t \mathrm{GH} 124$ was shifted by $+2-3^{\circ} \mathrm{C}$ when transition metals such as copper, nickel, manganese or iron were tested. Similar behaviour has also been replicated in other buffers and at other $\mathrm{pH}$ values (data not shown). 


\subsection{Isothermal titration calorimetry}

To investigate further the interaction between $R t \mathrm{GH} 124$ and metals, ITC experiments were carried out. The manganese

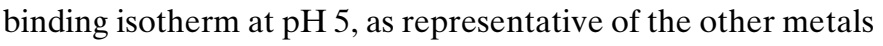
tested, is depicted in Fig. 3. The reactions were exothermic (with the exception of $\mathrm{Cu}^{2+}$ which was endothermic) and $\mathrm{Ca}^{2+}$ showed no binding (over the range tested from $\mathrm{pH} 5$ to $\mathrm{pH} 7$; see Table 5), in accord with the fluorimetry results. The low stoichiometries $(N \simeq 0.5)$ on metal binding may reflect partial modification of the metal-coordinating histidine (discussed below).

\subsection{Three-dimensional structure of RtGH124}

As originally described in the seminal publication by Brás et al. (2011), RtGH124 is composed of seven $\alpha$-helices surrounding an eighth (Fig. $4 a$ ) which contains the catalytic acid Glu203 (Glu96 in Brás et al., 2011). The metal-ion site (Fig. $4 c$ ) is located far from the catalytic area, and thus no impact has been observed on hydrolytic activity in the presence of different metals (data not shown). Manganese is coordinated by Asp141, Gln172, Glu175, His176, His264 and a water molecule. In several structures with other metals, the water is at a very low occupancy or is absent, while Glu175 is often found in a double conformation, with only one of its positions coordinating the metal. The reasons for this are unclear: it may reflect $\mathrm{pH}$ (5-6), the partial metal occupancy or histidine modification. As mentioned above, high-resolution structures of RtGH124 (1.40-0.94 ̊) have revealed an unambiguous modification of $\mathrm{C} 2$ of His264 (His157 in Brás et $a l ., 2011)$. In the case of manganese, the metal and the His264 modification both display partial occupancies of 0.7 and 0.3 ,

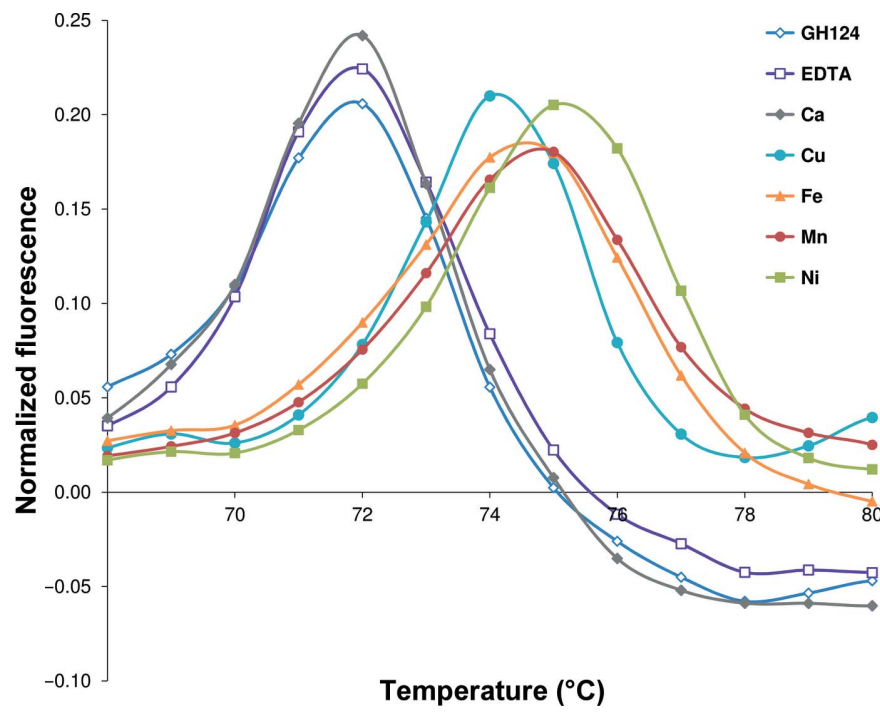

Figure 2

Differential scanning fluorimetry is represented as normalized fluorescence as a function of temperature. Controls with protein only (GH124) and EDTA are compared with samples containing one equivalent of each metal, i.e. calcium, copper, iron, manganese or nickel. Both controls and the sample with calcium show a maximum in fluorescence at $\sim 72^{\circ} \mathrm{C}$. The melting temperature is shifted to $74-75^{\circ} \mathrm{C}$ in the presence of transition metals.
Table 5

Isothermal titration calorimetry values at $\mathrm{pH}$ 5.0.

\begin{tabular}{lcccl}
\hline & $N$ & $K_{\mathrm{d}}(\mu M)$ & $\Delta H\left(\mathrm{cal} \mathrm{mol}^{-1}\right)$ & $\Delta S\left(\mathrm{cal} \mathrm{mol}^{-1} \mathrm{~K}^{-1}\right)$ \\
\hline $\mathrm{Mn}$ & 0.8 & 386 & 3.77 & 15.6 \\
$\mathrm{Fe}$ & 0.5 & 37 & 4.05 & 20.3 \\
$\mathrm{Ni}$ & 0.5 & 621 & 1.52 & 14.7 \\
$\mathrm{Cu}$ & 0.5 & 7 & -4.34 & 23.6 \\
\hline
\end{tabular}

respectively. Occupancy values were similar for other metals under similar conditions, varying from 0 to 0.5 for the histidine modification and from 0 to 0.8 for the metal. X-ray fluorescence spectra proved to be a powerful, but seldom conclusive, tool: several metals were usually found in each sample, along with the one added in the crystallization condition, with nickel appearing in all of the spectra as a common metal. These contaminants are likely to be derived from the purification steps or buffers used for the crystallization conditions. In the case of manganese this appeared to be the main metal in the sample, with only some residual nickel (Fig. 4b). It is worth

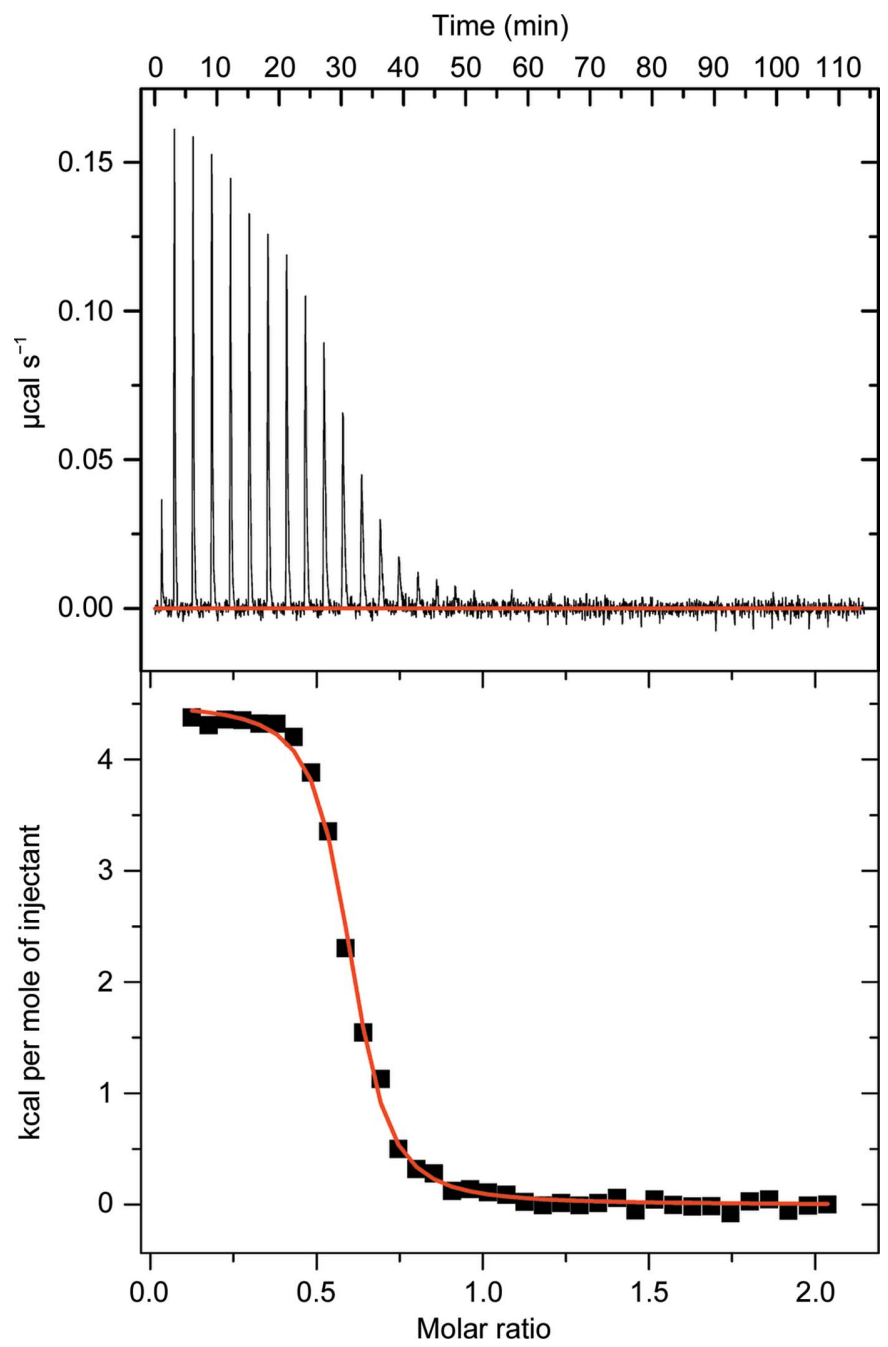

Figure 3

Representative ITC experiment: titration of manganese(II) acetate with $R t \mathrm{GH} 124$. The upper panel depicts raw binding heats and the baseline (in red). The lower panel shows corrected integrated heats and the fit to a single-site binding model (red line). 
noting that this technique reveals which metals are present in the cryoloop and not solely what is present in the metal-ion site.

\subsection{Mass spectrometry of the covalent modification}

To assess the nature of the histidine modification, massspectrometric assays were carried out. ESI-MS (Fig. 5a) clearly shows two main peaks corresponding to a mixture of modified and unmodified protein. The difference between the peaks is $16 \mathrm{Da}$, corresponding to the extra $\mathrm{O}$ atom in the modified species. To confirm that the modification was indeed in His264, LC-MS/MS analysis was performed after RtGH124 proteolysis (Fig. $5 b$ ). This technique provided unequivocal evidence of the modification taking place in His264, observed as a gap of 16 Da between each pair of peaks (unoxidized and oxidized forms) for peptides containing this residue (HMGIR to GISVHMGIR). Thus, the combination of crystallographic and MS techniques allowed it to be determined that this modified residue 264 is indeed 2-oxohistidine [note that what is called '2-oxohistidine', $\mathrm{PDB}$ residue ID OHI, reflects two chemically different species which would give rise to mass shifts of +14 or +16 ; what is observed here is the +16 species (Fig. 5c) as described in Schöneich (2000) and observed in the Bacillus subtilis PerR structure (Traoré et al., 2009)]. The fact that the oxidation is only partial could be a factor affecting the ITC stoichiometry, especially in light of the loss of metal binding by PerR upon oxidation (at one of its two 2-oxohistidine residues).

Amino-acid modification, and histidine oxidation in particular, is a well known feature in nature (Schöneich, 2006). Histidine has been extensively reported as being one of the most susceptible amino acids to free-radical reactions mediated by (transition) metals, mainly when they are in close proximity (Uchida \& Kawakishi, 1993; Schöneich, 2000; Hovorka et al., 2002; Lam et al., 2010). The modified 2-oxihistidine has been reported as an oxidative stress marker both in aerobic and (facultative) anaerobic microorganisms (Uchida \& Kawakishi, 1993; Ahn \& Baker, 2016; Sethu et al., 2016). In PerR, the protein functions as a metal-dependent $\mathrm{H}_{2} \mathrm{O}_{2}$ sensor.

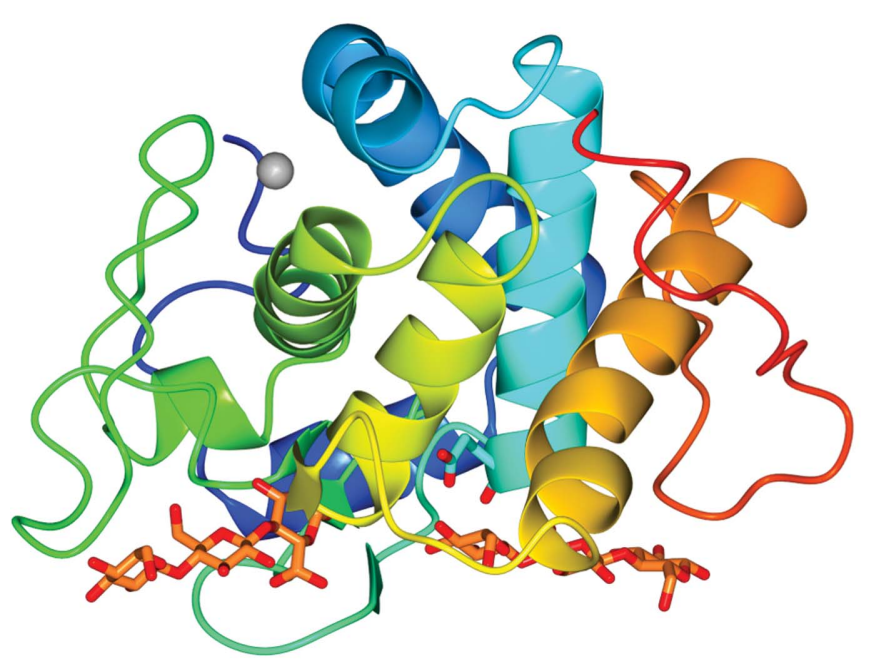

(a)

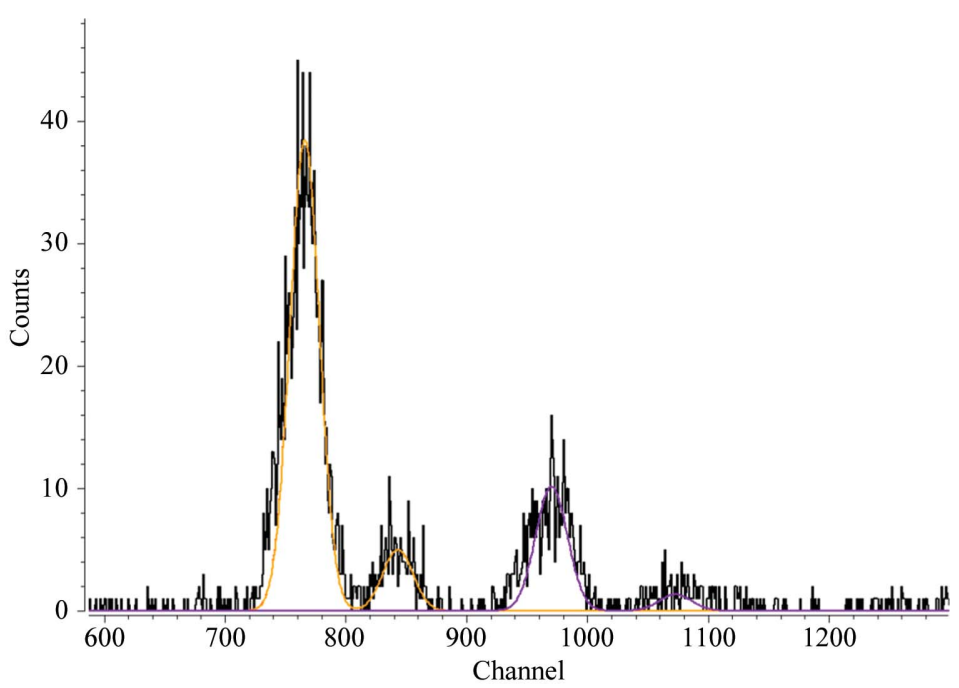

(b)
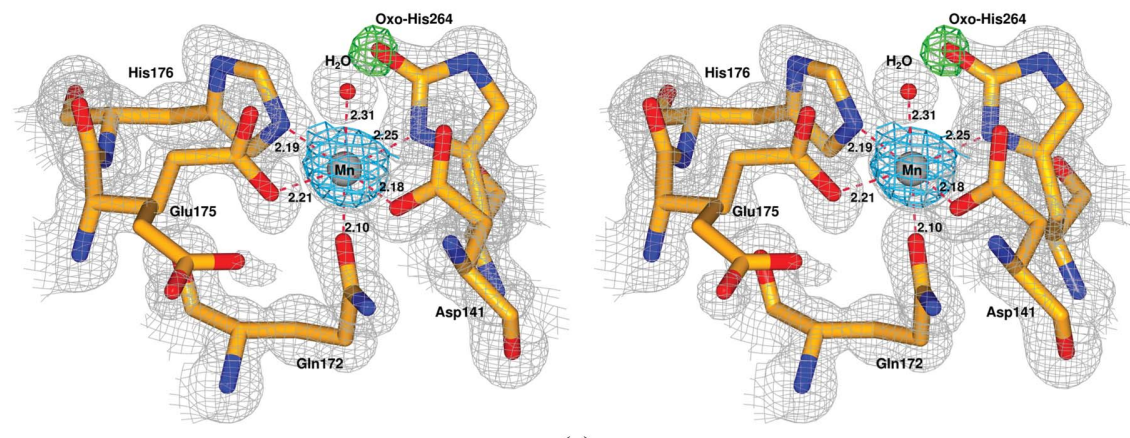

(c)

Figure 4

Three-dimensional structure of $R t \mathrm{GH} 124$ and metal-ion site. (a) General rainbow view of $R t \mathrm{GH} 124$ (PDB entry $6 \mathrm{~g} 1 \mathrm{~g}$ ) from red (N-terminus) to blue (C-terminus) in complex with two co-crystallized cellotrioses (in orange) next to the catalytic Glu203 (in light blue) and manganese (grey sphere) at the metal-ion site. (b) X-ray fluorescence spectrum for PDB entry 6g1g. Peaks corresponding to manganese and nickel are shown as yellow and purple lines, respectively. (c) Stereoview of the metal-ion site. The $2 F_{\mathrm{o}}-F_{\mathrm{c}}$ electron-density map (grey mesh) is contoured at $1 \sigma\left(0.44\right.$ e $\left.\AA^{-3}\right)$. The $F_{\mathrm{o}}-F_{\mathrm{c}}$ difference OMIT map (green mesh), calculated without the 2-oxo modification in His 264 , is contoured at $3 \sigma\left(0.36\right.$ e $\AA^{-3}$ ). The anomalous map (blue mesh) is likewise contoured at $3 \sigma\left(0.36 \mathrm{e}^{-3}\right)$. Distances between the metal and the coordinating atoms of Asp141, Gln172, Glu175, His176, His264 and the water are shown as red dashed lines. 


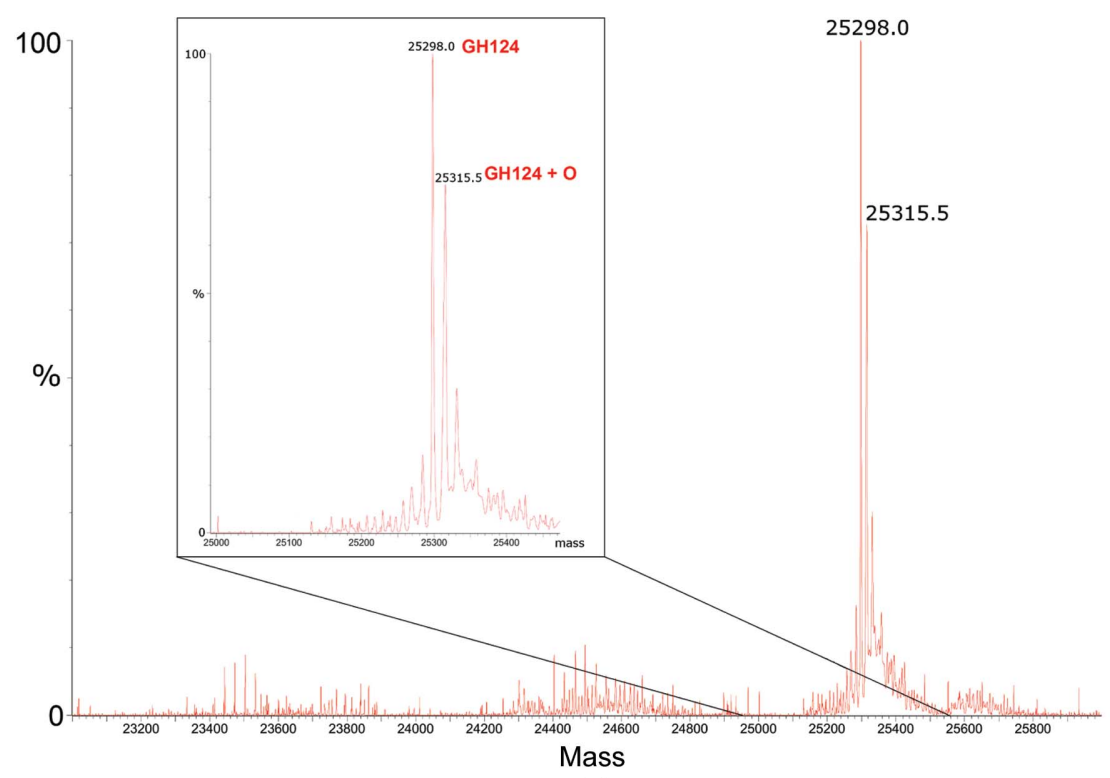

(a)

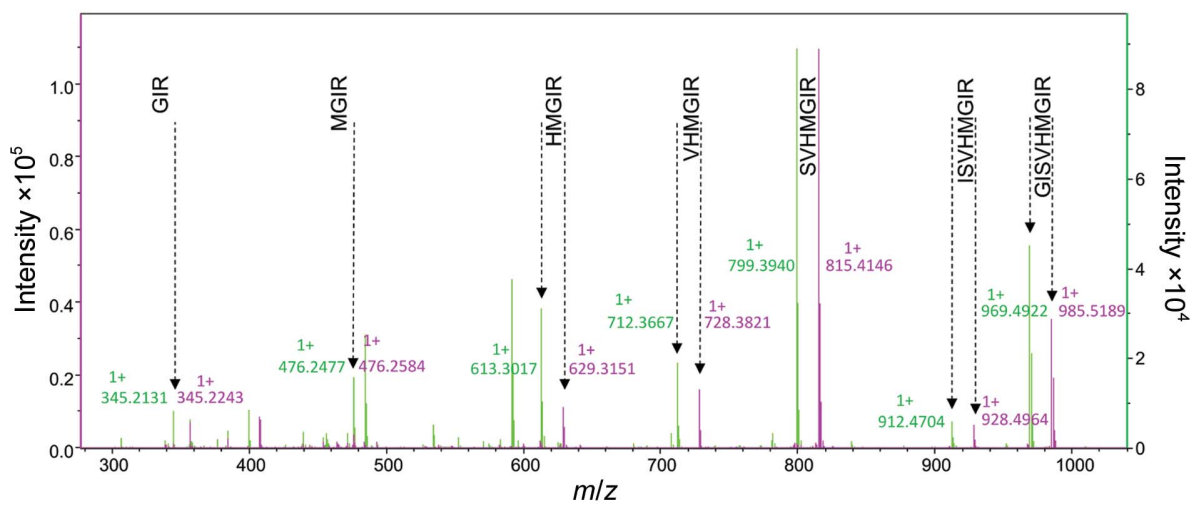

(b)

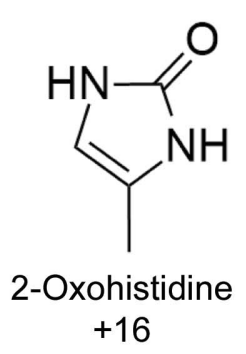

(c)

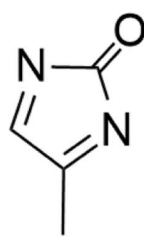

$+14$

Figure 5

Mass spectrometry was performed on cleaved (non-His-tagged) RtGH124 to study the His264 modification. (a) ESI-MS, general and enlarged (inset) spectra. The two main peaks indicate a mixture of non-oxidized (calculated, $25304 \mathrm{Da}$; observed, $25298 \mathrm{Da}$ ) and oxidized (calculated, $25320 \mathrm{Da}$; observed, $25315 \mathrm{Da}$ ) forms. The difference in the observed and calculated sizes is within the error range for this technique. $(b)$ The peptide resulting from the proteolysis of cleaved RtGH124 (GISVHMGIR) was analysed by LC-MS/MS. A mixture of unoxidized (in green) and oxidized (in pink) forms was also observed as a shift of $16 \mathrm{Da}$ in the peaks of peptides containing His264. (c) The form of ' 2 -oxohistidine' observed here is that which gives the +16 mass shift [as described in Schöneich (2000) and observed in the B. subtilis PerR structure (Traoré et al., 2009)] and not the chemically distinct +14 species.

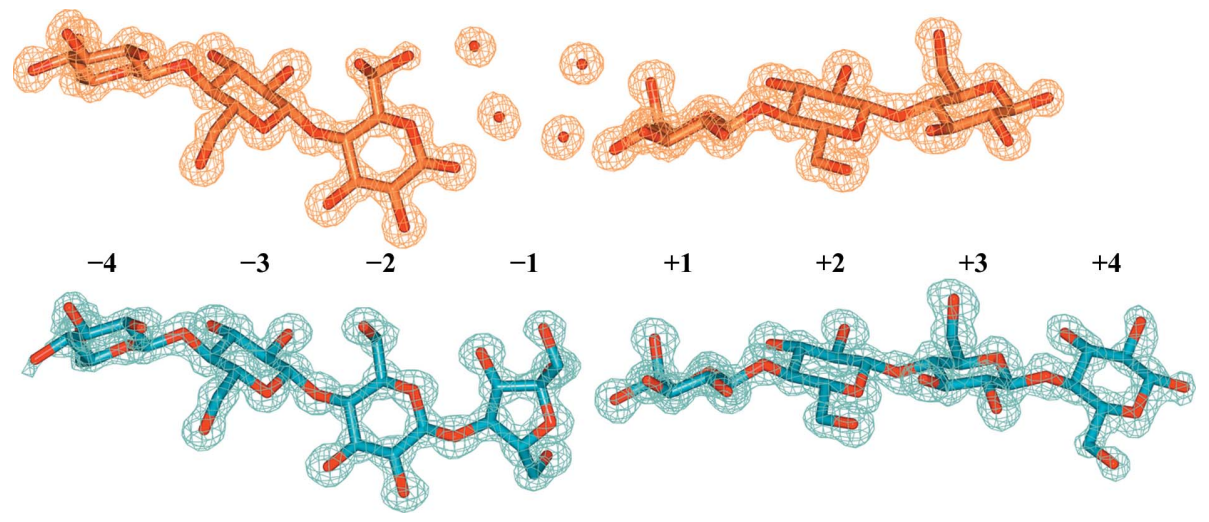

Figure 6

Comparison of the sugars found in the catalytic site. When co-crystallized with G3 (above, orange), two cellotrioses were found on either side of the catalytic residue, with the chains separated by several water molecules. When co-crystallized with the G5F-contaminated cellohexaose substrate (below, blue) no cleavage was found. Furthermore, the fructose unit substituted the waters that were very well defined in the previous structure. 


\subsection{Observation of a fructosylated oligosaccharide}

Structures of RtGH124 co-crystallized with cellotriose (G3) showed an active site with two cellotrioses and two water molecules hydrogen-bonded to either $\mathrm{O} 1$ of glucose in the first chain or $\mathrm{O} 4$ of glucose in the second chain (Fig. 6, in orange), akin to the structure reported by Brás et al. (2011). In structures co-crystallized with our original batch of cellohexaose a very unusual and unexpected fructosylated oligosaccharide (which we term G5F) was observed in the active site (Fig. 6b, blue).

Clear electron density indicated that the reducing-end sugar was not glucose, as expected, but a 1-4-linked fructose moiety. The hexasaccharide appears not to be cleaved, as four to six molecules of each chain have been observed in all of the structures (data not shown). Enzyme subsites -4 to -1 are occupied by one molecule and +1 to +4 by another, with both of them stabilized in the crystal by a second molecule in the same asymmetric unit.

Our initial thought was that the fructosylated oligosaccharide would be likely to represent a very minor contaminant in the G6 preparation, one somehow selected by the enzyme owing to tighter binding and/or inhibitory potential. We therefore speculated that it must bind very tightly and thus that fructosylated oligosaccharides might represent a new class of glycosidase inhibitor. With this in mind, two new $\beta-1,4$ ligands were synthesized to test as putative GH124 inhibitors: Glc-Fru (GF) and Glc-Glc-Fru (GGF). However, no crystals could be obtained by cocrystallization with either of these ligands, and no binding was detectable using ITC.

Given the apparent lack of binding of GGF to RtGH124, we sought to test whether our assumption that the G5F is a tightbinding, but extremely minor, contaminant was correct. Digestion of cellohexaose samples, both those suspected of containing G5F and a newly purchased batch (believed to be fructose-free), was performed using a GH1 $\beta$-glucosidase from Thermotoga maritima. The monosaccharide content was detected by both high-performance anion-exchange chromatography (HPAEC) and the glucose/mannose/fructose detection kit from Megazyme. The originally purchased G6 sample contained an approximately 1:1 ratio of G6 and G5F (but subsequently purchased batches were 100\% G6), highlighting that the unusual observed species was simply a contaminant in the commercial supply of G6 available at that time.

\section{Conclusions}

$R t \mathrm{GH} 124$ is the defining member of CAZY family GH124. The original publication highlighted its catalytic activity as an unusual inverting cellulose. Unusually for $R$. thermocellum, $R t \mathrm{GH} 124 \mathrm{~A}$ is not targeted to the multi-enzyme cellulosome complex of the organism but instead consists of a 'dockerin' domain which instead targets the enzyme to the cell surface of the bacterium, followed by a CAZY GH124 catalytic domain; $R t \mathrm{Gh} 124$ is therefore an unusual enzyme if its primary role is in cellulose degradation yet it is not part of the cellulose complex. The presence of a partial occupied covalently modified histidine in a site that binds a variety of transition metals is therefore intriguing. Histidine 2-oxidation is normally associated with oxidative stress response elements (see, for example, Traoré et al., 2009) and has not, to our knowledge, previously been witnessed on-enzyme. Mass spectrometry shows it is present in the protein as expressed and is not a feature of X-ray exposure of the crystal. Whether it plays a role in stress signalling in $R$. thermocellum is solely a matter for conjecture, but it serves to highlight both the difficulty in assigning metal-ion sites in proteins and the potential for more, unusual, metal-ion sites that have gone unnoticed; most notably in the (L)PMO enzymes where the metal ion and histidine modification hid in plain sight for many years.

\section{Acknowledgements}

We thank Diamond Light Source (DLS) for granting access to beamline I02 (mx-13587), which contributed to the results presented here, and their staff for onsite assistance. Author contributions are as follows. SU performed the experimental work. AC performed the ligand analysis. FL, working in the group of Steve Withers, synthesized the substrates. PHW and GJD conceived and supervised the study. All authors contributed to writing the paper.

\section{Funding information}

This work was funded by the Biotechnology and Biological Sciences Research Council (grant BB/L021633/1).

\section{References}

Agirre, J., Iglesias-Fernández, J., Rovira, C., Davies, G. J., Wilson, K. S. \& Cowtan, K. D. (2015). Nature Struct. Mol. Biol. 22, 833-834. Ahn, B. E. \& Baker, T. A. (2016). Proc. Natl Acad. Sci. USA, 113, E23-E31.

Brás, J. L. A., Cartmell, A., Carvalho, A. L. M., Verzé, G., Bayer, E. A., Vazana, Y., Correia, M. A. S., Prates, J. A. M., Ratnaparkhe, S., Boraston, A. B., Romao, M. J., Fontes, C. M. G. A. \& Gilbert, H. J. (2011). Proc. Natl Acad. Sci. USA, 108, 5237-5242.

Bunkóczi, G. \& Read, R. J. (2011). Acta Cryst. D67, 303-312.

Chruszcz, M., Domagalski, M., Osinski, T., Wlodawer, A. \& Minor, W. (2010). Curr. Opin. Struct. Biol. 20, 587-597.

Emsley, P., Lohkamp, B., Scott, W. G. \& Cowtan, K. (2010). Acta Cryst. D66, 486-501.

Harris, P. V., Welner, D., McFarland, K. C., Re, E., Navarro Poulsen, J.-C., Brown, K., Salbo, R., Ding, H., Vlasenko, E., Merino, S., Xu, F., Cherry, J., Larsen, S. \& Lo Leggio, L. (2010). Biochemistry, 49, 3305-3316.

Hicks, K. B., Symanski, E. V. \& Pfeffer, P. E. (1983). Carbohydr. Res. 112, 37-50.

Horn, S. J., Vaaje-Kolstad, G., Westereng, B. \& Eijsink, V. G. (2012). Biotechnol. Biofuels, 5, 45-57.

Hovorka, S. W., Biesiada, H., Williams, T. D., Hühmer, A. \& Schöneich, C. (2002). Pharm. Res. 19, 530-537.

Kabsch, W. (2010). Acta Cryst. D66, 125-132.

Karkehabadi, S., Hansson, H., Kim, S., Piens, K., Mitchinson, C. \& Sandgren, M. (2008). J. Mol. Biol. 383, 144-154.

Kim, Y.-W., Lee, S. S., Warren, R. A. J. \& Withers, S. G. (2004). J. Biol. Chem. 279, 42787-42793. 
Lam, A. K., Hutton, C. A. \& O'Hair, R. A. (2010). Rapid Commun. Mass Spectrom. 24, 2591-2604.

Levasseur, A., Drula, E., Lombard, V., Coutinho, P. M. \& Henrissat, B. (2013). Biotechnol. Biofuels, 6, 41-54.

Lo Leggio, L., Welner, D. \& De Maria, L. (2012). Comput. Struct. Biotechnol. J. 2, e201209019.

McNicholas, S., Potterton, E., Wilson, K. S. \& Noble, M. E. M. (2011). Acta Cryst. D67, 386-394.

Murshudov, G. N., Skubák, P., Lebedev, A. A., Pannu, N. S., Steiner, R. A., Nicholls, R. A., Winn, M. D., Long, F. \& Vagin, A. A. (2011). Acta Cryst. D67, 355-367.

Phillips, C. M., Beeson, W. T. IV, Cate, J. H. \& Marletta, M. A. (2011). ACS Chem. Biol. 6, 1399-1406.

Potterton, L. et al. (2018). Acta Cryst. D74, 68-84.

Quinlan, R. J. et al. (2011). Proc. Natl Acad. Sci. USA, 108, 1507915084.

Schöneich, C. (2000). J. Pharm. Biomed. Anal. 21, 1093-1097.

Schöneich, C. (2006). Exp. Gerontol. 41, 807-812.

Sethu, R., Goure, E., Signor, L., Caux-Thang, C., Clemancey, M., Duarte, V. \& Latour, J. M. (2016). ACS Chem. Biol. 11, 1438-1444.

Solé, V. A., Papillon, E., Cotte, M., Walter, P. \& Susini, J. (2007). At. Spectrosc. 62, 63-68.

Span, E. A. \& Marletta, M. A. (2015). Curr. Opin. Struct. Biol. 35, $93-$ 99.
The CAZypedia Consortium (2018). Glycobiology, 28, 3-8.

Traoré, D. A. K., El Ghazouani, A., Jacquamet, L., Borel, F., Ferrer, J.-L., Lascoux, D., Ravanat, J.-L., Jaquinod, M., Blondin, G., CauxThang, C., Duarte, V. \& Latour, J.-M. (2009). Nature Chem. Biol. 5, 53-59.

Uchida, K. \& Kawakishi, S. (1993). FEBS Lett. 332, 208-210.

Vaaje-Kolstad, G., Horn, S. J., van Aalten, D. M. F., Synstad, B. \& Eijsink, V. G. H. (2005). J. Biol. Chem. 280, 2849228497.

Vaaje-Kolstad, G., Westereng, B., Horn, S. J., Liu, Z., Zhai, H., Sørlie, M. \& Eijsink, V. G. H. (2010). Science, 330, 219-222.

Vagin, A. \& Teplyakov, A. (2010). Acta Cryst. D66, 22-25.

Walton, P. H. \& Davies, G. J. (2016). Curr. Opin. Chem. Biol. 31, 195207.

Winter, G. (2010). J. Appl. Cryst. 43, 186-190.

Yutin, N. \& Galperin, M. Y. (2013). Environ. Microbiol. 15, 26312641.

Zheng, H., Chordia, M. D., Cooper, D. R., Chruszcz, M., Müller, P., Sheldrick, G. M. \& Minor, W. (2014). Nature Protoc. 9, 156170.

Zheng, H., Chruszcz, M., Lasota, P., Lebioda, L. \& Minor, W. (2008). J. Inorg. Biochem. 102, 1765-1776.

Zheng, H., Cooper, D. R., Porebski, P. J., Shabalin, I. G., Handing, K. B. \& Minor, W. (2017). Acta Cryst. D73, 223-233. 